\title{
Primary extranodal marginal zone lymphoma of mucosa-associated lymphoid tissue with multiple pure ground-glass opacities: a case report
}

Xuebing Ding ${ }^{1,2}$, Takashi Makino' ${ }^{1}$ Satoshi Koezuka ${ }^{1}$, Takashi Azumi ${ }^{1}$, Hajime Otsuka', Yoshinobu Hata',

Yuichi Shinya ${ }^{3}$, Naobumi Tochigi $i^{4}$, Kazutoshi Shibuya ${ }^{4}$ and Akira lyoda ${ }^{1 *}$ (D)

\begin{abstract}
Background: Primary pulmonary mucosa-associated lymphoid tissue (MALT) lymphoma is a low-grade B cell lymphoma that is a type of non-Hodgkin lymphoma and a type of primary pulmonary malignant lymphoma. MALT lymphomas affecting the lung show various findings on chest computed tomography, which range from typical nodules or areas of consolidation to findings that are extremely rare in pulmonary MALT lymphomas, such as pure ground-glass opacities throughout the lung.

Case presentation: A 35-year-old woman was found to have a few shadows with ground glass opacities on chest computed tomography (CT) in 2012. A shadow in right S10 that was initially very small increased in size over time, and was $14 \times 8 \mathrm{~mm}$ in 2015. Other shadows also appeared. Because lung adenocarcinoma was suspected, the patient underwent video-assisted thoracoscopic surgery with a right wedge resection of the lower lobe that included the largest nodule in S10 and other nodules. Histopathological examination of the right S10 and other lesions revealed small- or medium-sized lymphocyte-like cells that were located in the alveolar interseptal spaces. The alveolar walls remained intact. Immunohistochemical staining showed that tumor cells were positive for CD20, CD79a, and BCL2 expression. The lesions were diagnosed as extranodal marginal zone B-cell lymphoma of MALT.

Conclusions: We think that the ground glass opacities on CT were accounted for by MALT lesions that contained intact alveolar air spaces. The patient has remained well during 12 months of follow up after surgery. Although she did not receive chemotherapy because the MALT lymphoma lesions have been stable without progression, the patient is kept under close observation because of potential progression of the disease.
\end{abstract}

Keywords: Extranodal marginal zone lymphoma, Mucosa-associated lymphoid tissue, Multiple, Ground-glass opacity

\section{Background}

Pulmonary extranodal marginal zone lymphoma of mucosa-associated lymphoid tissue (MALT) is a type of primary pulmonary malignant lymphoma with monoclonal B cells, and infiltrates the bronchiolar mucosal epithelium, forming lymphoepithelial lesions [1]. Patients with MALT lymphoma may have nonspecific symptoms and can also be asymptomatic [2]. Chest computed tomography $(\mathrm{CT})$

\footnotetext{
* Correspondence: aiyoda@med.toho-u.ac.jp

${ }^{1}$ Division of Chest Surgery, Toho University School of Medicine, Tokyo, Japan Full list of author information is available at the end of the article

findings of MALT lymphomas occurring in the lung range from typical nodules or areas of consolidation to findings that are extremely rare, such as pure ground-glass opacities (GGOs) [2]. Here, we report a patient with growth and many GGOs.

\section{Case presentation}

A 35-year-old woman was found to have a few shadows with GGOs on chest CT in 2012. She was monitored and a shadow in right S10 was found to increase in size, which suggested lung adenocarcinoma. The patient was 
referred to our hospital for further evaluation. The patient had a history of bronchial asthma. The shadow in right S10 had increased to $14 \times 8 \mathrm{~mm}$ by 2015 (Fig. 1). Other shadows also appeared (Fig. 2). After preoperative CT-guided marking, the patient underwent videoassisted thoracoscopic surgery with a right wedge resection of the lower lobe that included the largest nodule in S10 and other nodules. Her postoperative course was uneventful.

Grossly, the surgical specimen contained pale, somewhat yellow lesions (Fig. 3). Histopathological examination of the right S10 lesion and other nodules revealed small- or medium-sized lymphocyte-like cells that were located in the alveolar interseptal spaces. The alveolar walls remained intact (Fig. 4a, b). Immunohistochemical staining showed that tumor cells were positive for CD20 (1:400 dilution; DAKO, Carpinteria, CA, USA, Fig. 4c), CD79a (1:200 dilution; DAKO, Carpinteria, CA, USA), and BCL2 (1:50 dilution; DAKO, Carpinteria, CA, USA, Fig. 4d) expression and negative for CD10 (1:50 dilution; Novocastra, Newcastle upon Tyne, UK), cyclin D1 (1:75 dilution; DAKO, Carpinteria, CA, USA) and CD30 (1:40 dilution; DAKO, Carpinteria, CA, USA). The lesions were diagnosed as extranodal marginal zone B-cell lymphoma of MALT. The patient has remained well during 12 months of follow up after surgery. Although she did not receive chemotherapy because the MALT lymphoma lesions have been stable without progression, the patient is kept under close observation because of potential progression of the disease.

\section{Discussion}

Extranodal lymphomas, frequently found in the gastrointestinal tract, occur in less than $5 \%$ of patients with Hodgkin lymphoma and up to $33 \%$ with non-Hodgkin lymphoma [3].

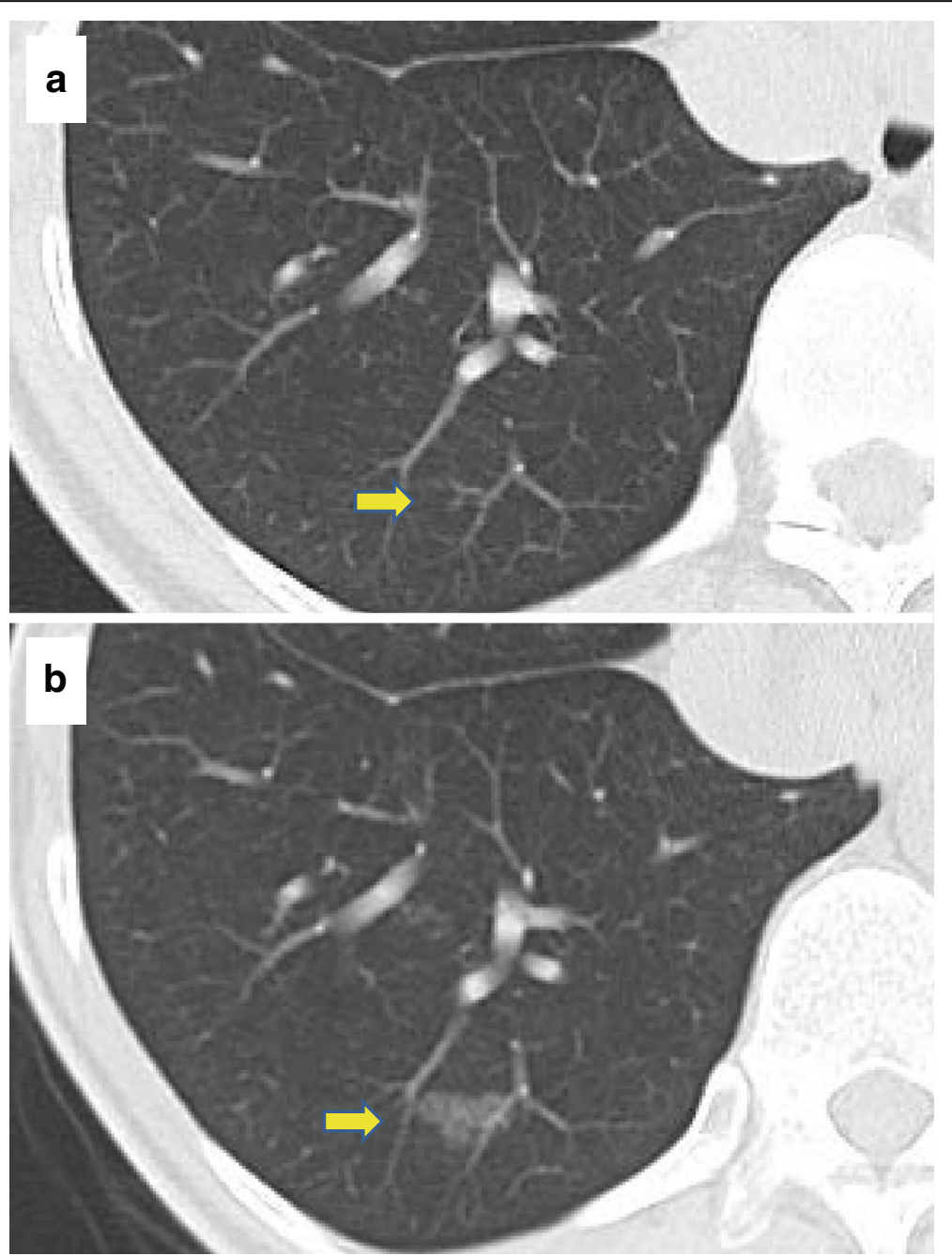

Fig. 1 Chest computed tomography in 2012 revealed a very small shadow with ground glass opacity (arrow) that increased in size over time. a in 2012 (b) in 2015 


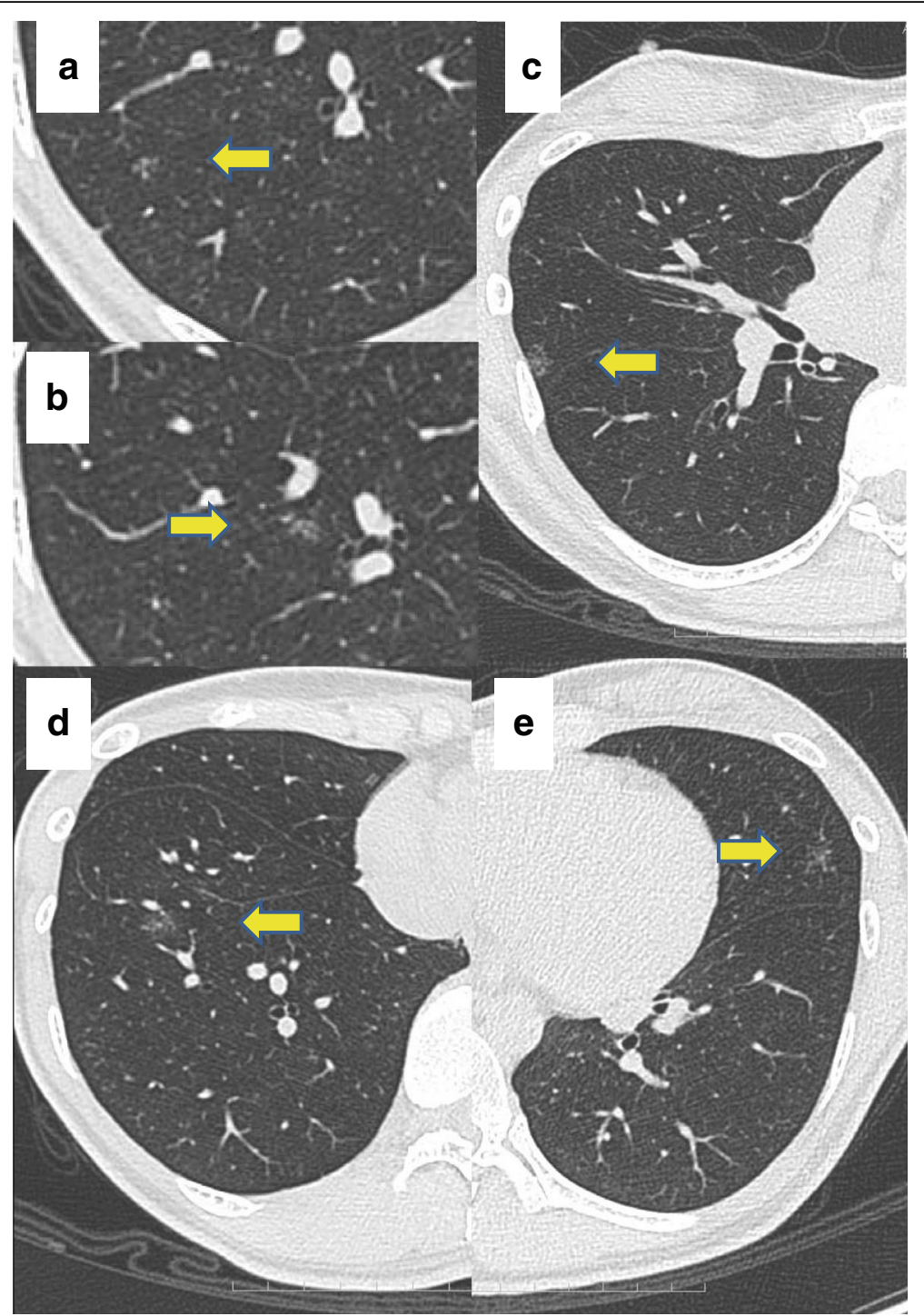

Fig. 2 Chest computed tomography in 2015 also revealed multiple shadows with ground glass opacities $\mathbf{a}$, b in right lower lobe, $\mathbf{c}$ in right middle lobe, $\mathbf{d}$ in segment 8 of right lower lobe, and $\mathbf{e}$ in left upper lobe

Primary pulmonary lymphoma is defined as lymphoma with involvement of the lung, lobar, or primary bronchus, with or without mediastinal involvement, and no evidence of extrathoracic lymphoma at the time of diagnosis or for 3 months thereafter [4]. It is an extremely rare neoplasm, accounting for $0.5 \%$ of all primary pulmonary malignancies [5], 3-4\% of extranodal non-Hodgkin lymphoma, and less than $1 \%$ of nonHodgkin's lymphoma [6].

In chest $\mathrm{CT}$, the usual finding of primary pulmonary MALT lymphoma is bilateral and multiple, nearly all lesions contain clear areas corresponding to an intact bronchial lumen with sometimes distended bronchi, and less than $10 \%$ of patients have bilateral diffuse reticulonodular opacities, atelectasis or pleural effusion [7]. In our patient, the CT lesions appeared as pure GGOs. With the increasing use of low-dose screening CT, increasing numbers of small lung cancers with focal GGOs are being detected [8]. GGO means an area of a homogeneous hazy increase in density that does not obscure the bronchovascular structure in the lung field on thinsection CT [9]. GGOs have been reported in $0.2-0.5 \%$ of screened populations [9]. Localized GGOs that persist for months have been reported to correspond to precancerous lesions such as atypical adenomatous hyperplasia and early-stage adenocarcinomas such as bronchioloalveolar carcinoma [9]. Identification and management of persistent pure GGOs that appear on CT are difficult. In our patient, after monitoring her by repeated CT imaging, we interpreted her findings as suspicious for lung 


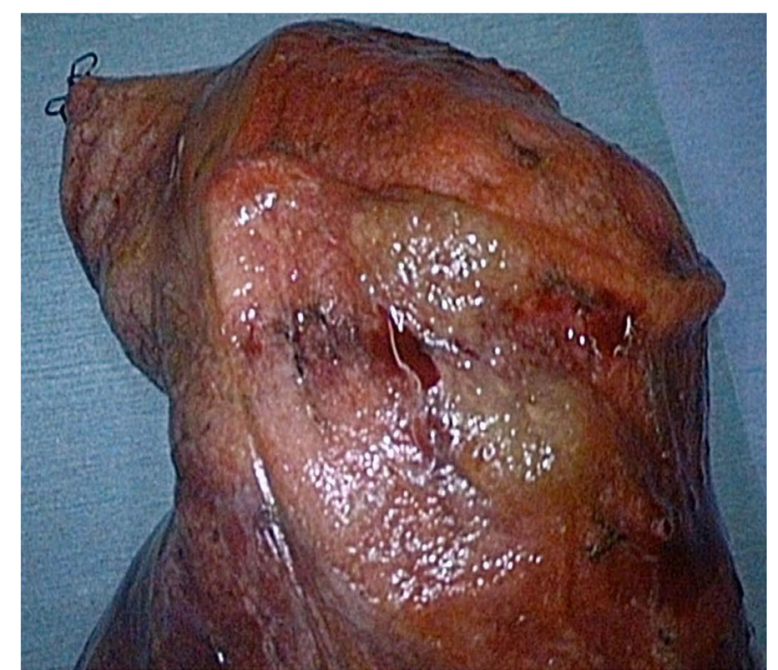

Fig. 3 The surgical specimen revealed a yellowish tumor

adenocarcinoma. However, pathological findings in our case revealed pulmonary extranodal marginal zone Bcell lymphoma of MALT.

Pulmonary MALT lymphoma manifesting as multiple pure GGOs is extremely rare. In our case, we think that GGOs on CT were accounted for by MALT lesions that contained intact alveolar air spaces.

Pulmonary MALT lymphoma usually has an indolent course, remaining localized in the lung for long periods before dissemination [10]. Ahmed et al. studied 22 cases of bronchial-associated lymphoid tissue lymphoma, and they concluded that bronchial-associated lymphoid tissue lymphoma responds well to local or systemic therapy and has a relatively good prognosis [10]. Troch et al. performed follow up without treatment for patients with pulmonary MALT lymphoma. They concluded that it was a very indolent disease, with the potential for spontaneous regression, and that asymptomatic patients with MALT lymphoma might not require immediate treatment [11]. Because our patient had multiple pulmonary lesions, complete excision was difficult; we performed limited thoracoscopic surgical resection for diagnosis only. Instead of surgical excision or chemotherapy for our patient, we are monitoring her other bilateral, slowgrowing GGOs. She has remained well during 12 months of follow up after surgery, and all the lesions are stable without progression.

\section{Conclusions}

We reported a case of pulmonary extranodal marginal zone B-cell lymphoma of MALT, with CT features of multiple pure GGOs, which is extremely rare. We think that the ground glass opacities on CT were accounted for by MALT lesions that contained intact alveolar air spaces. The patient has remained well during 12 months of follow up after surgery. Although she did not receive chemotherapy because the MALT lymphoma lesions have been stable without progression, the patient is kept under close observation because of potential progression of the disease.

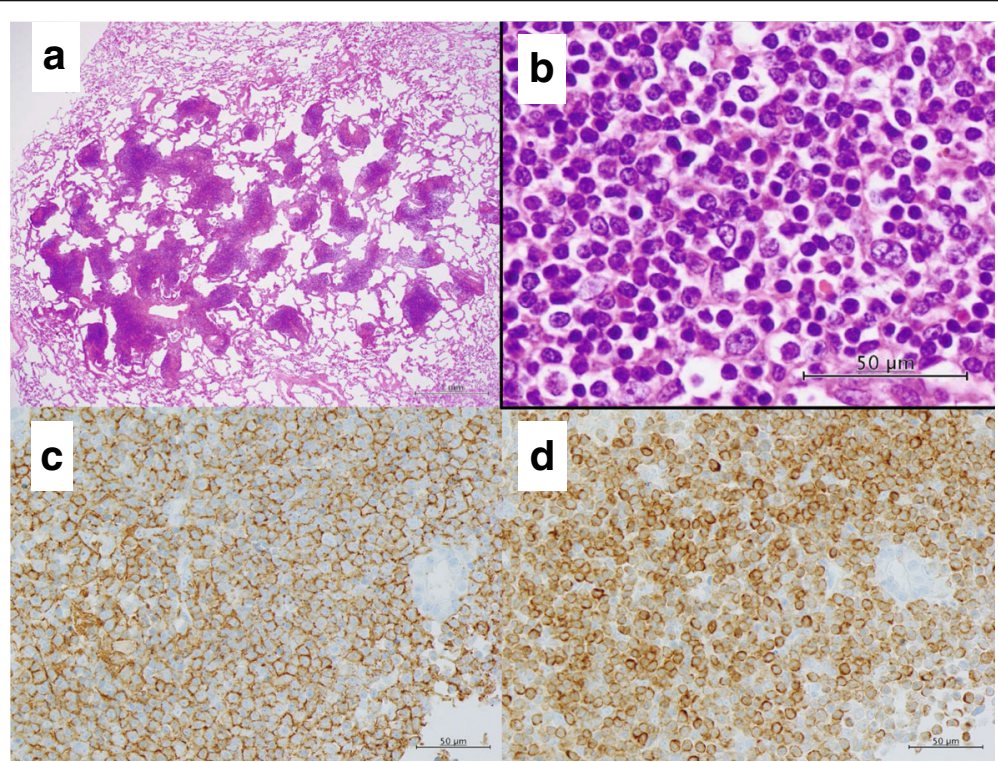

Fig. 4 a Pathological findings revealed tumor cells that were located in alveolar interseptal spaces. The alveolar walls remained intact. b Tumor cells showed slight atypia with hyperchromatic nuclei. Lymphoepithelial lesions were observed in the specimen. $\mathbf{c}$ Tumor cells were positive for CD20 expression. d Tumor cells were positive for BCL2 expression 


\section{Abbreviations}

CT: Computed tomography; GGO: Ground-glass opacity; MALT: Mucosa-associated lymphoid tissue

\section{Acknowledgements}

Not applicable.

\section{Funding}

This study was supported in part by JSPS KAKENHI Grant Number JP 15 K10272.

\section{Availability of data and materials}

The data supporting the conclusions of this article are included within the article.

\section{Authors' contributions}

All authors participated in the design of the case report and coordination, and helped to draft the manuscript. XD, TM and Al wrote the manuscript. SK, $\mathrm{TA}, \mathrm{HO}, \mathrm{YH}$ and $\mathrm{YS}$ collected clinical data of the patient and analyzed those. NT and KS carried out the pathological diagnosis and made pathological figures. All authors read and approved the final manuscript.

\section{Competing interests}

The authors declare that they have no competing interests.

\section{Consent for publication}

Written informed consent was obtained from the patient for publication of this case report and any accompanying images. A copy of the written consent is available for review by the Editor-in-Chief of the Journal of Cardiothoracic Surgery.

\section{Ethics approval and consent to participate}

Not required.

\section{Disclosures}

The authors have no funding, financial relationships, or conflicts of interest to disclose.

\section{Author details}

${ }^{1}$ Division of Chest Surgery, Toho University School of Medicine, Tokyo, Japan. ${ }^{2}$ Department of Cardiothoracic Surgery, Affiliated Suzhou Hospital of Nanjing Medical University, Suzhou, China. ${ }^{3}$ Shinya Clinic, Kanagawa, Japan.

${ }^{4}$ Department of Surgical Pathology, Toho University School of Medicine,

Tokyo, Japan.

Received: 2 September 2016 Accepted: 19 January 2017

Published online: 25 January 2017

\section{References}

1. Travis WD, Brambilla E, Burke A, Marx A, Nicholson A. WHO Classification of Tumours of the Lung, Pleura, Thymus and Heart. 4th ed. Lyon: IARC; 2015.

2. Noguchi S, Yatera K, Kido T, Ogoshi T, Nagata S, Nishida C, et al. Pulmonary mucosa-associated lymphoid tissue (MALT) lymphoma with multiple thinwalled pulmonary cysts: a case report and review of the literature. Intern Med. 2013:52:2325-9.

3. Halliday T, Baxter G. Lymphoma: pictorial review. I. Eur Radiol. 2003;13:1154-64

4. Yoshino N, Hirata T, Takeuchi C, Usuda J, Hosone M. A case of primary pulmonary diffuse large B cell lymphoma diagnosed by transbronchia biopsy. Ann Thorac Cardiovasc Surg. 2015;21:396-8.

5. Cherian SV, Thampy E, Mauzo SH. Primary pulmonary lymphoma: a case of 'unresolving pneumonia'. Am J Med. 2014;127:e3-4.

6. Shinoda K, Taki H, Tsuda T, Hayashi R, Nomoto K, Tobe K. Primary pulmonary lymphoma presenting with multiple lung nodules. Am J Respir Crit Care Med. 2014;190:e30-1.

7. Cadranel J, Wislez M, Antoine M. Primary pulmonary lymphoma. Eur Respir J. 2002;20:750-62.

8. Lu CH, Hsiao CH, Chang YC, Lee JM, Shih JY, Wu LA, et al. Percutaneous computed tomography-guided coaxial core biopsy for small pulmonary lesions with ground-glass attenuation. J Thorac Oncol. 2012;7:143-50.

9. Hiramatsu M, Inagaki T, Inagaki T, Matsui Y, Satoh Y, Okumura S, et al. Pulmonary ground-glass opacity (GGO) lesions-large size and a history of lung cancer are risk factors for growth. J Thorac Oncol. 2008;3:1245-50.
10. Ahmed S, Kussick SJ, Siddiqui AK, Bhuiya TA, Khan A, Sarewitz S, et al. Bronchial-associated lymphoid tissue lymphoma: a clinical study of a rare disease. Eur J Cancer. 2004;40:1320-6.

11. Troch M, Streubel B, Petkov V, Turetschek K, Chott A, Raderer M. Does MALT lymphoma of the lung require immediate treatment? An analysis of 11 untreated cases with long-term follow-up. Anticancer Res. 2007;27:3633-7.

\section{Submit your next manuscript to BioMed Central and we will help you at every step:}

- We accept pre-submission inquiries

- Our selector tool helps you to find the most relevant journal

- We provide round the clock customer support

- Convenient online submission

- Thorough peer review

- Inclusion in PubMed and all major indexing services

- Maximum visibility for your research

Submit your manuscript at www.biomedcentral.com/submit
) Biomed Central 